\title{
Sustained hip flexion contracture after femoral lengthening in patients with achondroplasia
}

\author{
Mi Hyun Song, Tae-Jin Lee, Jong Hyeop Song and Hae-Ryong Song ${ }^{*}$ (D)
}

\begin{abstract}
Background: Hip flexion contracture often occurs after femoral lengthening in patients with achondroplasia, but few studies have investigated its development in these patients. The purpose of this study was to analyze sustained hip flexion contracture in achondroplasia patients who underwent femoral lengthening and to identify contributing factors.

Methods: This study included 34 patients with achondroplasia who underwent femoral lengthening (mean age at operation, 11.1 years). Sustained hip flexion was defined as flexion contracture lasting $>6$ months postoperatively despite physiotherapy. Demographic data, spinopelvic parameters (pelvic incidence, pelvic tilt, sacral slope, lumbar lordosis, and sagittal vertical axis), and quantitative assessments of femoral lengthening were investigated. The associations among these factors and the development of sustained hip flexion contracture were assessed.

Results: Sustained hip flexion contracture developed in 13 (38\%) of 34 achondroplasia patients after femoral lengthening. Eight (62\%) of these 13 patients concomitantly exhibited limitation of knee flexion. Excessive femoral lengthening (odds ratio [OR], 1.450; 95\% confidence interval [Cl], 1.064 to 1.975; $p=0.019$ ) and forward sagittal vertical axis tilt $(\mathrm{OR}, 1.062 ; 95 \% \mathrm{Cl}, 1.001$ to $1.127 ; p=0.047)$ contributed to sustained hip flexion contracture.

Conclusions: Sustained hip flexion contracture frequently occurs after femoral lengthening in achondroplasia patients. Both excessive femoral lengthening and preoperative forward SVA tilt may contribute to the development of sustained hip flexion contracture in these patients.
\end{abstract}

Keywords: Hip, Flexion contracture, Achondroplasia, Femoral lengthening

\section{Background}

Achondroplasia is the most common skeletal dysplasia, with an incidence of one in every 30,000 live births annually [1]. Clinical features of achondroplasia are spinopelvic deformities, such as thoracolumbar kyphosis and lumbosacral hyperlordosis [2-4], and rhizomelic short stature $[1,5,6]$. Rhizomelic short stature in patients with achondroplasia is an appropriate indication for femoral lengthening to reduce functional impairment and improve quality of life $[7,8]$, because intramembranous ossification mechanism remains intact in achondroplasia.
However, excessive femoral lengthening can lead to complications, including contracture of adjacent joints, delayed callus formation and consolidation, and fracture of the regenerate bones $[9,10]$. Hip flexion contracture is one of the most serious complications and frequently requires surgical treatment despite physiotherapy $[7,8$, $11,12]$. Nevertheless, few studies have systematically analyzed the development of hip flexion contracture after femoral lengthening in achondroplasia. The purpose of this study was to analyze sustained hip flexion contracture after femoral lengthening in achondroplasia patients and to identify contributing factors.

\section{Methods}

Department of Orthopaedic Surgery and Institute for Rare Diseases, Korea University Medical Center, Guro Hospital, 148 Gurodong-ro, Guro-gu, Seoul 152-703, Republic of Korea

Patients who were diagnosed with achondroplasia and underwent simultaneous bilateral femoral lengthening at 
our institute from 2004 to 2015 were included. Patients who had undergone femoral lengthening at another institute before referral, underwent tibial lengthening only, had other medical co-morbidities (such as disorders related to bone metabolism and neuromuscular disorders), or had incomplete medical records and radiographs were excluded. A total of 34 patients were enrolled. The mean age at femoral lengthening was 11.1 years (6.8-21.5 years), and the patients were followed up for 5.0 years (2.0-11.1 years).

\section{Surgical technique}

Femoral lengthening was performed by the senior surgeon (HRS) using a monolateral external fixator (Dyna-Extor, BK Meditech, Seoul, Korea) (Fig. 1). Before surgery, the patients were recommended performing limb lengthening of 30 to $40 \%$ of the initial segment length. Three Schanz screws were inserted into the proximal and distal ends of the femur perpendicular to the anatomic axis under fluoroscopic guidance. At the mid-diaphyseal level, a transverse osteotomy was performed with the multiple-drill-hole method. After 7 days of latent period, femoral lengthening was initiated at a rate of $0.25 \mathrm{~mm}$ every $6 \mathrm{~h}$. The lengthening rate was adjusted according to the morphologic features of the callus [11, 12]. The external fixator was removed after a bridging callus was observed at 3 of 4 cortices on plain radiographs. A thigh brace was used for 4 to 6 weeks to prevent a regenerate fracture. Patients were followed up every week during the first month, every 2 weeks during the lengthening period, and then monthly during the consolidation period.

\section{Physiotherapy protocol}

Passive range of motion (ROM) exercises of hip and knee joints were started on postoperative day 3. Simultaneously, the patients were encouraged to bear weight with the use of crutches. Active ROM exercises of adjacent joints were started on postoperative day 7 . The patients were instructed to perform their exercise gently 3 times a day for $20 \mathrm{~min}$. They were recommended to gradually increasing ROM and weight bearing as tolerated. In patients with restricted active ROM, passive and active-assisted ROM exercises were recommended priorly.

For patients with hip flexion contracture, hip extension exercise in the prone position was performed under a guidance of well-trained physician. The patients were instructed to perform their exercise 5 times a week at least $1 \mathrm{~h}$, moreover, to be prone position on sleep.

\section{Outcome measurements}

All patients measured their hip and knee ROM before surgery and at each period of the lengthening process. In addition, the existence of the hip flexion contracture was determined by the Thomas test $[12,13]$. The Thomas test was performed with the patient in a supine position on a firm physical examination table. The uninvolved limb was adequately flexed to eliminate anterior pelvic tilt (PT) [14]. Concomitant knee joint stiffness was also assessed in every patient.

Patients were grouped into the hip flexion contracture group or the no significant contracture group based on the occurrence of sustained hip flexion contracture after femoral lengthening. Sustained hip flexion contracture was defined as a hip flexion contracture which lasted more than 6 months postoperatively despite intensive physiotherapy as well as which required soft tissue release eventually. All the soft tissue surgeries were performed during the consolidation period. For the soft tissue release, intramuscular recession of the rectus femoris [11] was mainly performed. Additionally, intramuscular recession of sartorius and iliopsoas and partial release of iliotibial band were often accompanied. Immediate postoperative hip flexion contractures, which were improved only with physiotherapy, were not considered to be sustained hip flexion contractures.
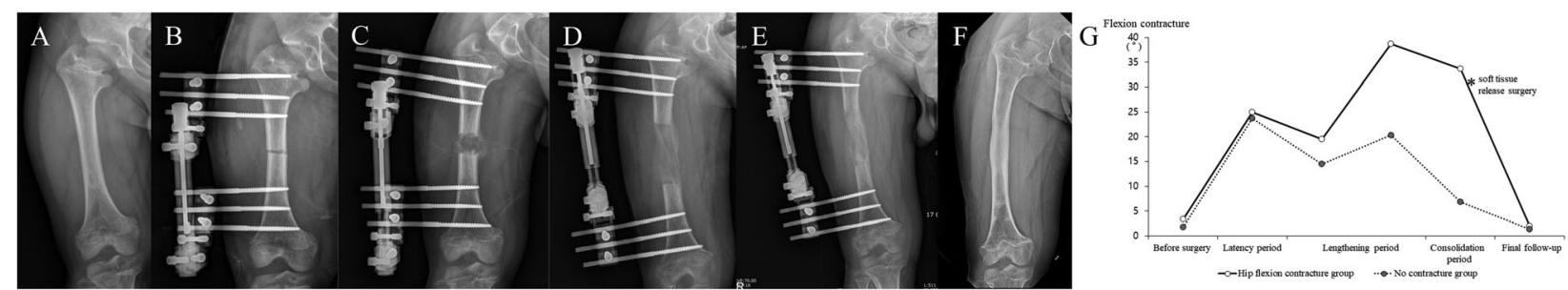

Fig. 1 Radiographs of the different stages of the lengthening procedure and average hip flexion contracture at each measurement period. a Preoperative radiograph of a 16-year-old boy with achondroplasia b) Radiograph during the latency period of the patient. $\mathbf{c}$ Radiograph at the early stage of lengthening period of the patient. $\mathbf{d}$ Radiograph at the end of lengthening period of the patient. The patient finally gained the length $9.5 \mathrm{~cm}$ by femoral lengthening (lengthening percentage of 30.2\%). e Radiograph during the consolidation period of the patient. $\mathbf{f}$ Radiograph after external fixator removal. The external fixator was removed after a bridging callus was observed at 3 of 4 cortices on plain radiographs. $\mathbf{g}$ Diagram of average hip flexion contracture for the entire patients during the each stage of the lengthening process. In the hip flexion contracture group, soft tissue release was performed during the consolidation period (*) 
To identify potential contributors associated with sustained hip flexion contracture after femoral lengthening in achondroplasia, the following variables were investigated: sex, age at operation, preoperative spinopelvic parameters including pelvic incidence (PI), PT, sacral slope (SS), lumbar lordosis (LL), and sagittal vertical axis (SVA), and quantitative assessments of femoral lengthening.

Spinopelvic parameters (PI, PT, SS, LL, and SVA) were measured on standing whole spine anteroposterior and lateral radiographs before femoral lengthening and at postoperative 6 months [2]. PI was defined as the angle between a perpendicular line to the sacral endplate and a line joining the middle of the sacral endplate and the hip axis (Fig. 2a), whereas PT was defined as the angle between the line joining the middle of the sacral endplate and the hip axis and a vertical line (Fig. 2b). SS was defined as the angle between the sacral superior endplate and the horizontal plane (Fig. 2c). LL was measured between the upper endplate of L1 and the upper endplate of S1 by using the Cobb method (Fig. 2d). SVA was defined as the horizontal distance between a plumb line dropped from the center of C7 to the posterior-superior corner of S1 (Fig. 2e).

Quantitative assessments of femoral lengthening were performed on a slit scanogram, as described by Bell and Thompson [15]. Initial femoral length, amount of lengthening, lengthening percentage, and external fixation index (EFI) were assessed. The lengthening percentage was defined as the amount of lengthening divided by the total length of the femur. The EFI was calculated as the duration of external fixation in days divided by the length gained in $\mathrm{cm}$.
Besides, complications, except adjacent joints stiffness, were also assessed, according to the Paley's classification [16]; which were subdivided into problem, obstacle, and sequel.

\section{Statistical analysis}

Continuous data were analyzed with the Mann-Whitney test; and categorical data, with the Fisher exact test. Comparative analyses were performed with the Wilcoxon signed-rank test. Multivariate logistic regression analysis was performed to identify the potential contributors to sustained hip flexion contracture; dependent variables were those with $p$-values $<0.05$ in univariate analysis or those with clinical significance. One side of the hip was randomly selected and statistically analyzed in all patients to avoid duplication of spinopelvic parameters. Statistical analyses were performed with SPSS version 21.0 (SPSS, IBM Corp., Chicago, IL); p-values $<0.05$ were regarded as statistically significant.

\section{Results}

Sustained hip flexion contracture occurred in 13 (38\%) of 34 patients who underwent femoral lengthening. The patients in the hip flexion contracture group already had significantly larger degrees of hip flexion contracture before surgery (Table 1). However, the majority of patients of the hip flexion contracture group exhibited aggravation of hip flexion contracture by the end of lengthening period $(p<0.001)$ (Fig. 1). In spite of massive physiotherapy, unsolved hip flexion contracture remained in patients of the hip flexion contracture group; they required

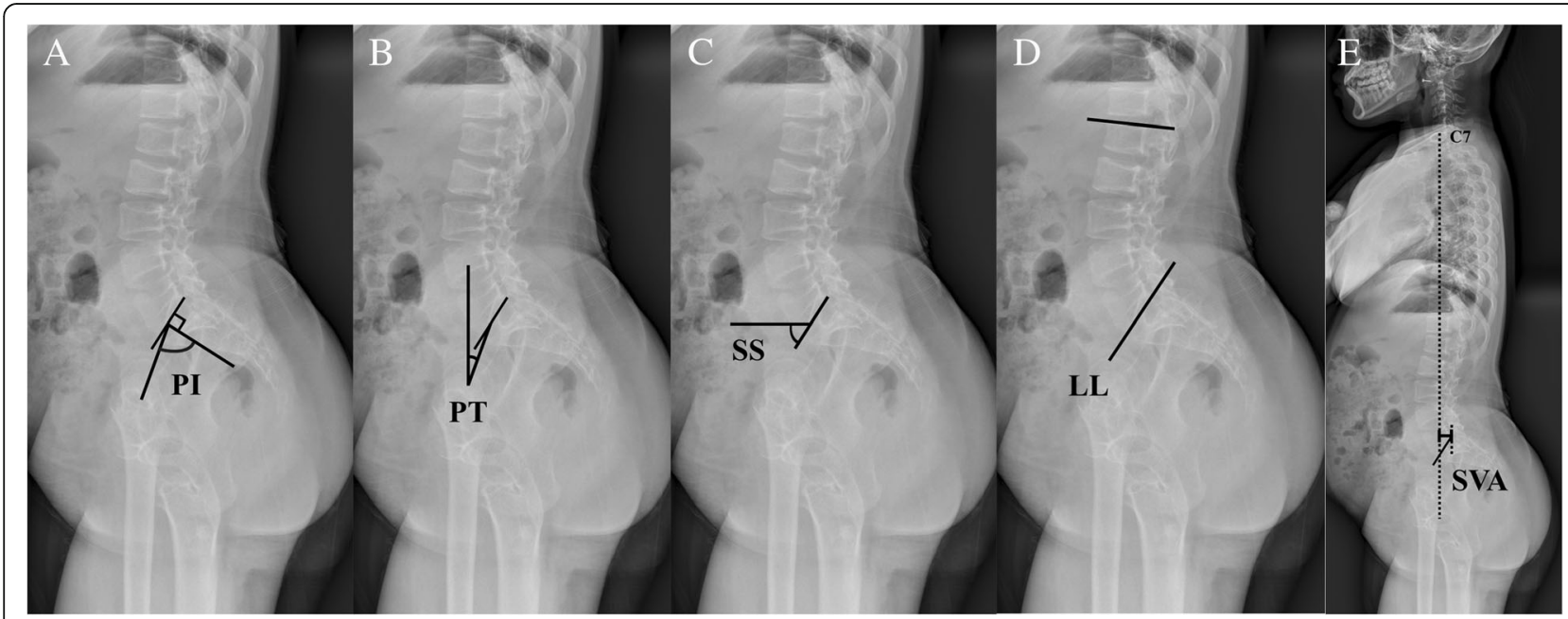

Fig. 2 Spinopelvic parameters measured on standing radiographs. a Pelvic incidence (PI) was defined as the angle between a perpendicular line to the sacral endplate and a line joining the middle of the sacral endplate and the hip axis. $\mathbf{b}$ Pelvic tilt (PT) was defined as the angle between the line joining the middle of the sacral endplate and the hip axis and a vertical line. c Sacral slope (SS) was defined as the angle between the sacral superior endplate and the horizontal plane. $\mathbf{d}$ Lumbar lordosis $(\mathrm{LL})$ was measured between the upper endplate of $\mathrm{L} 1$ and the upper endplate of S1 by using the Cobb method. e Sagittal vertical axis (SVA) was defined as the horizontal distance between a plumb line dropped from the center of C7 to the posterior-superior corner of S1 
Table 1 Comparison of the degree of hip flexion contracture between the hip flexion contracture and no significant contracture groups

\begin{tabular}{llll}
\hline Hip FC $\left(^{\circ}\right)$ & Hip FC group $(n=13)$ & No significant contracture group $(n=21)$ & $p$-value \\
\hline $\begin{array}{l}\text { Before surgery } \\
\text { During the distraction osteogenesis }\end{array}$ & $6.3(5-7)^{*}$ & $1.8(0-5)^{*}$ & $\mathbf{0 . 0 0 5 \dagger}$ \\
Latency period & $25.0(10-35)^{*}$ & $23.7(8-33)^{*}$ & 0.740 \\
Lengthening period (early) & $19.5(0-25)^{*}$ & $14.5(0-20)^{*}$ & 0.619 \\
Lengthening period (end) & $38.7(32-42)^{*}$ & $20.3(5-25)^{*}$ & $<\mathbf{0 . 0 0 1 \dagger}$ \\
Consolidation period & $33.7(30-35)^{*}$ & $6.8(0-15)^{*}$ & $<\mathbf{0 . 0 0 1 \dagger}$ \\
Final follow-up & $2.0(0-5)^{*}$ & $1.3(0-3)^{*}$ & 0.459 \\
\hline
\end{tabular}

FC flexion contracture

*Data presented in parenthesis represent the range

†Statistically significant

soft tissue release during the consolidation period. Eight (62\%) of 13 patients with hip flexion contracture exhibited knee stiffness concomitantly, especially in limitation of flexion. After soft tissue surgeries, all patients of the hip flexion contracture group recovered nearly full range of movement of the hip and knee joint with no significant hip flexion contracture (Fig. 1).

The characteristics of the patients with hip flexion contracture are summarized in Table 2. These patients underwent larger amount and percentages of femoral lengthening (averagely $10.1 \mathrm{~cm}$ and $43.5 \%$, respectively) compared to patients without contracture. In addition, they were more likely to show forward SVA tilt than patients without contracture.

The amount of lengthening and the preoperative SVA value were significantly associated with sustained hip flexion contracture. Excessive femoral lengthening increased the risk of sustained hip flexion contracture (odds ratio $[\mathrm{OR}], 1.450 ; 95 \%$ confidence interval $[\mathrm{CI}]$, 1.064 to $1.975 ; p=0.019)$. In addition, as the preoperative SVA shifted forwards, the risk of sustained hip flexion contracture increased (OR, 1.062; 95\% CI, 1.001 to $1.127 ; p=0.047$ ).

Perioperative spinopelvic parameters between hip flexion contracture and no significant contracture groups were in Table 3. In the hip flexion contracture group, a significant change in spinopelvic parameters developed during the femoral lengthening (Fig. 3): LL and SS were significantly increased $(p=0.001$ and 0.001 , respectively) postoperatively, whereas PT was decreased $(p=0.011)$. There were no significant interval changes in PI. In contrast, no significant interval changes in

Table 2 Comparative analyses of hip flexion contracture and no significant contracture groups

\begin{tabular}{|c|c|c|c|}
\hline & $\begin{array}{l}\text { Hip FC group } \\
(n=13)\end{array}$ & $\begin{array}{l}\text { No significant contracture group } \\
(n=21)\end{array}$ & $p$-value \\
\hline \multicolumn{4}{|l|}{ Demographic data } \\
\hline Gender & $4: 9$ & $8: 13$ & 0.665 \\
\hline Age at operation (years) & 10.6 years $(6.8-14.6)^{*}$ & 11.5 years $(6.8-21.5)^{*}$ & 0.917 \\
\hline \multicolumn{4}{|c|}{ Preoperative spinopelvic parameters } \\
\hline $\mathrm{PI}\left({ }^{\circ}\right)$ & $42.1(36.3-50.2)^{*}$ & $35.6(30.0-47.8)^{*}$ & 0.261 \\
\hline $\mathrm{PT}\left({ }^{\circ}\right)$ & $-2.5(-6.7-12.2)^{*}$ & $-3.6(-7.3-6.0)^{*}$ & 0.972 \\
\hline SS $\left({ }^{\circ}\right)$ & $44.6(37.4-55.6)^{*}$ & $39.1(22.1-47.0)^{*}$ & 0.120 \\
\hline LL ( $\left(^{\circ}\right)$ & $47.1(37.2-54.3)^{*}$ & $43.2(40.1-51.9)^{*}$ & 0.484 \\
\hline SVA $(\mathrm{mm})$ & $17.9(-17-35.0)$ & $-15.2(-47.0-40.0)$ & $0.005+$ \\
\hline \multicolumn{4}{|c|}{ Quantitative assessments of the femoral lengthening } \\
\hline Initial femoral length & $23.3 \mathrm{~cm}(20.2-26.2)^{*}$ & $25.2 \mathrm{~cm}(18.0-40.0)^{*}$ & 0.649 \\
\hline Amount of lengthening & $10.1 \mathrm{~cm}(7.6-13.6)^{*}$ & $8.1 \mathrm{~cm}(5.8-10.9)^{*}$ & $0.001 \dagger$ \\
\hline Lengthening percentage & $43.5 \%(36.5-52.1)^{*}$ & $33.3 \%(19.0-45.6)^{*}$ & $<0.001 t$ \\
\hline EFI (day/cm) & $35.7(21.8-56.6)^{*}$ & $41.4(23.3-60.0)^{*}$ & 0.309 \\
\hline
\end{tabular}

$F C$ flexion contracture, $P T$ pelvic tilt, $P I$, pelvic incidence, SS sacral slope, $L L$ lumbar lordosis, EFI external fixation index *Data presented in parenthesis represent the range tStatistically significant 
Table 3 Perioperative spinopelvic parameters between hip flexion contracture and no significant contracture groups

\begin{tabular}{|c|c|c|c|c|c|c|}
\hline & \multicolumn{3}{|l|}{$\begin{array}{l}\text { Hip FC group } \\
(n=13)\end{array}$} & \multicolumn{3}{|c|}{$\begin{array}{l}\text { No significant contracture group } \\
(n=21)\end{array}$} \\
\hline & Preoperative & postoperative & $p$-value & preoperative & postoperative & $p$-value \\
\hline $\mathrm{PI}\left({ }^{\circ}\right)$ & $42.1(36.3-50.2)^{*}$ & $53.3(29.2-65.5)$ & 0.068 & $35.6(30.0-47.8)^{*}$ & $36.0(28.5-52.1)$ & 0.317 \\
\hline PT $\left(^{\circ}\right)$ & $-2.5(-6.7-12.2)^{*}$ & $-5.0(-26.0-24.0)$ & $0.011 \dagger$ & $-3.6(-7.3-6.0)^{*}$ & $-3.0(-26.0-17.0)$ & 0.317 \\
\hline SS $\left(^{\circ}\right)$ & $44.6(37.4-55.6)^{*}$ & $74.3(45.0-107.0)$ & $0.001 \dagger$ & $39.1(22.1-47.0)^{*}$ & $40.0(20.0-72.0)$ & 0.919 \\
\hline $\mathrm{LL}\left({ }^{\circ}\right)$ & $47.1(37.2-54.3)^{*}$ & $66.7(45.0-87.0)$ & $0.001 \dagger$ & $43.2(40.1-51.9)^{*}$ & $48.0(40.8-66.0)$ & 0.281 \\
\hline
\end{tabular}

FC flexion contracture, PT, pelvic tilt, PI pelvic incidence, SS sacral slope, LL lumbar lordosis

*Data presented in parenthesis represent the range

†Statistically significant

spinopelvic parameters developed in the no significant contracture group (Fig. 4).

Complications of the hip flexion contracture and no significant contracture groups were as follows. In the hip flexion contracture group, refracture developed in 8 patients after external fixator removal. They underwent external fixator reapplication using an intramedullary nailing with or without bone grafting. Two patients had varus angular deformity and underwent osteotomy for acute correction. One patient exhibited superficial pin site infection which required treatment with oral antibiotics. In contrast, 7 cases of refracture and 1 case of varus angular deformity developed in the no significant contracture group; the treatment method of each complication was same as that of the hip flexion contracture group. Additionally, one patient had deep surgical site infection. Local debridement was done in the operation room. There were no cases of limb length discrepancy at postoperation in both groups.

\section{Discussion}

Patients with achondroplasia have unique pelvic and spinal structures. They exhibit a pelvis that is shaped like a champagne glass and has an anterior PT [17]. With regards to the spine, kyphosis at the thoracolumbar junction is very frequent in infants and mostly resolves when the child begins to walk [2-4]. As kyphosis begins to improve, lumbosacral hyperlordosis may begin to progress [17]. Hence, the spinopelvic parameters of patients with achondroplasia differ from those of the average population: they are more likely to have higher thoracolumbar kyphosis and LL as well as lower PT and thoracic kyphosis [2-4]. As a result, patients with achondroplasia are at greater risk of developing hip flexion contracture

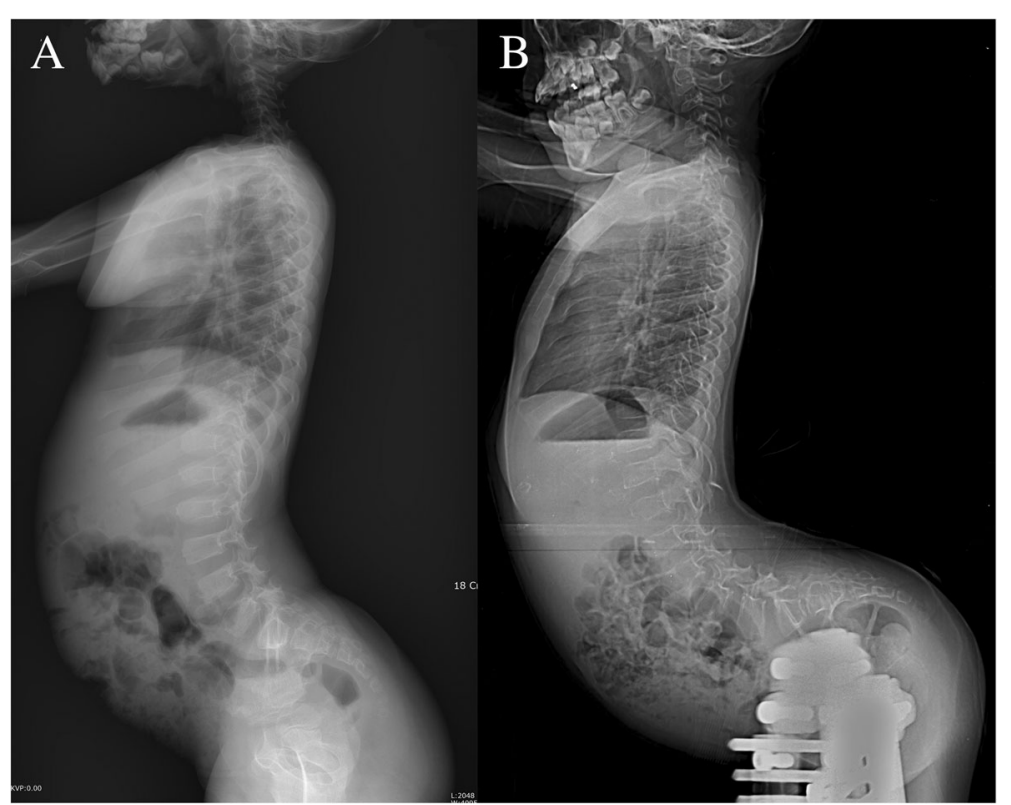

Fig. 3 Radiographs of a 10-year-old boy with achondroplasia exhibiting sustained hip flexion contracture after femoral lengthening. a Initial radiograph of the patient. The patient underwent simultaneous bilateral femoral lengthening to gain $11 \mathrm{~cm}$ (lengthening percentage of $42.9 \%$ ). $\mathbf{b}$ Postoperative radiograph showing an aggravation of the horizontal sacrum with lumbosacral hyperlordosis 


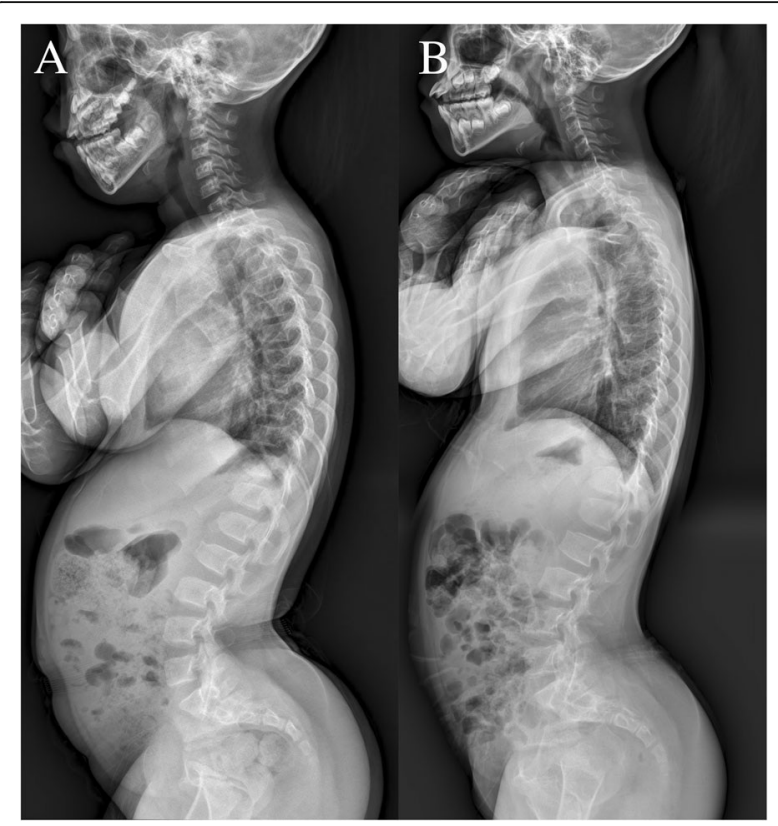

Fig. 4 Radiographs of a 16-year-old achondroplasia patient not exhibiting flexion contracture after femoral lengthening. a Initial radiograph of the patient. The patient underwent simultaneous bilateral femoral lengthening to gain $6 \mathrm{~cm}$ (lengthening percentage of 19.0\%). b Postoperative radiograph showing no significant changes of spinopelvic parameters in comparison with initial radiograph

than the average population. Indeed, we previously demonstrated that hip flexion contracture often occurs after femoral lengthening in achondroplasia patients [11, 12].

We found that excessive femoral lengthening was a significant contributor to sustained hip flexion contracture after femoral lengthening in achondroplasia patients. This result is consistent with previous reports. Many authors have recommended lengthening the bony segment from 20 to $30 \%$ of its initial length to prevent complications [10, 18-20]. We previously demonstrated that adjacent joint contracture is more common when femoral lengthening is greater than $50 \%$ in achondroplasia patients [12]. This occurs because excessive distraction osteogenesis beyond muscle elasticity induces substantial irreversible muscle damage with fibrosis, inflammation, and necrosis [20-22]. In the present study, femoral osteotomy was performed in the mid-diaphyseal region, so damage could have arisen in the quadriceps and hamstring muscles [23, 24].

Hong et al. [2] demonstrated that pelvic parameters (PI, SS, and PT) are closely related to spinal parameters (thoracic kyphosis, LL, and thoracolumbar kyphosis) in achondroplasia patients, and that these relationships play an important role in achieving sagittal balance. Besides, the trunk of achondroplasia patients tends to backward tilt (mean SVA, $-22.2 \mathrm{~mm}$ ) to compensate for lumbar hyperlordosis [25]. However, the present study indicated that preoperative forward SVA tilt is another contributor to sustained postoperative hip flexion contracture. The authors postulated the reasons that patients who have preoperative forward SVA tilt might have be at greater risk of pre-existing hip flexion contracture and quadriceps shortening before femoral lengthening.

Postoperatively, patients with sustained hip flexion contracture showed a significant change in spinopelvic parameters, including an increase in SS and LL and a decrease in PT. In addition, most patients had knee stiffness, especially in limitation of flexion. These findings suggest that the quadriceps muscles, mainly the rectus femoris, may be the main origin of the hip flexion contracture. Tightness and stiffness of the quadriceps muscles induce an imbalance of muscle force around the pelvis and compensatory anterior pelvic tilt, which sequentially leads to a significant increase in SS and lumbar hyperlordosis. Moreover, this may eventually cause deterioration of perioperative hip flexion contracture in these patients [25]. This could explain why all patients having sustained hip flexion contracture underwent soft tissue release, including intramuscular recession of the rectus femoris, and recovered near full range of motion of the hip joint as a consequence.

This study had several limitations. First, the sample size was not large enough. Second, hip flexion contracture was confirmed by the Thomas test only, instead of accompanying the gait analysis. These limitations were inevitable due to the rarity of achondroplasia and the retrospective study design. Nevertheless, all patients in our series were surgically treated by a single surgeon at a single institution with a long-term follow-up. In addition, it is important to note that this study is the first attempt to analyze the sustained hip flexion contracture after femoral lengthening in achondroplasia patients.

\section{Conclusions}

Sustained hip flexion contracture is frequent after femoral lengthening in achondroplasia patients. Both excessive femoral lengthening and preoperative forward SVA tilt may contribute to the development of sustained hip flexion contracture in these patients. It would be better for surgeons to consider preemptive soft tissue surgery during femoral lengthening in achondroplasia patients of these situations.

\section{Abbreviations}

EFI: external fixation index; LL: lumbar lordosis; PI: pelvic incidence; PT: pelvic tilt; SS: sacral slope; SVA: sagittal vertical axis

\section{Acknowledgments}

We thank Jae-Hyuk Yang and Sung Hyun Noh for invaluable assistance with the manuscript. 


\section{Funding}

No benefits in any form have been or will be received from a commercial party related directly or indirectly to the subject of this article.

\section{Availability of data and materials}

The dataset supporting the conclusion of this study is available upon request to the corresponding author.

\section{Authors' contributions}

MHS participated in the collection and assembly of data, analysis and interpretation of the data, and drafting of the article. TJL participated in the collection and assembly of data and analysis and interpretation of the data. JHS participated in the collection and assembly of data and critical revision of the article. HRS participated in designing the study, preparing the manuscript, and providing final approval of the article. All authors have read and approved the manuscript.

\section{Ethics approval and consent to participate}

This study was approved by Korea university medical center Guro hospital institutional review board (Human Research Protection Program Center; IRB No. 2018GR0020; IRB-approved on January 26, 2018). The study was performed in accordance with the Helsinki Declaration of 1983. The relevant ethics committee exempted this study from the requirement to obtain informed consent of patients after a waiver of informed consent was submitted with a detailed explanation.

\section{Competing interests}

The authors have no competing interests that could potentially or inappropriately influence this study.

\section{Publisher's Note}

Springer Nature remains neutral with regard to jurisdictional claims in published maps and institutional affiliations.

\section{Received: 20 February 2018 Accepted: 15 November 2018}

Published online: 29 November 2018

\section{References}

1. Shirley ED, Ain MC. Achondroplasia: manifestations and treatment. J Am Acad Orthop Surg. 2009;17(4):231-41.

2. Hong JY, Suh SW, Modi HN, Park JW, Park JH. Analysis of sagittal spinopelvic parameters in achondroplasia. Spine (Phila Pa 1976). 2011;36(18):E1233-9.

3. Karikari IO, Mehta Al, Solakoglu C, Bagley CA, Ain MC, Gottfried ON. Sagittal spinopelvic parameters in children with achondroplasia: identification of 2 distinct groups. J Neurosurg Spine. 2012;17(1):57-60.

4. Kopits SE. Thoracolumbar kyphosis and lumbosacral hyperlordosis in achondroplastic children. Basic Life Sci. 1988:48:241-55.

5. Carter EM, Davis JG, Raggio CL. Advances in understanding etiology of achondroplasia and review of management. Curr Opin Pediatr. 2007; 19(1):32-7.

6. Haga N. Management of disabilities associated with achondroplasia. J Orthop Sci. 2004;9(1):103-7.

7. Kim SJ, Balce GC, Agashe MV, Song SH, Song HR. Is bilateral lower limb lengthening appropriate for achondroplasia?: midterm analysis of the complications and quality of life. Clin Orthop Relat Res. 2012;470(2):616-21.

8. Aldegheri R, Dall'Oca C. Limb lengthening in short stature patients. J Pediatr Orthop B. 2001;10(3):238-47.

9. Paley D. Current techniques of limb lengthening. J Pediatr Orthop. 1988; 8(1):73-92.

10. Yun AG, Severino R, Reinker K. Attempted limb lengthenings beyond twenty percent of the initial bone length: results and complications. J Pediatr Orthop. 2000;20(2):151-9.

11. Park KW, Garcia RA, Rejuso CA, Choi JW, Song HR. Limb lengthening in patients with achondroplasia. Yonsei Med J. 2015;56(6):1656-62.

12. Venkatesh KP, Modi HN, Devmurari K, Yoon JY, Anupama BR, Song HR. Femoral lengthening in achondroplasia: magnitude of lengthening in relation to patterns of callus, stiffness of adjacent joints and fracture. J Bone Joint Surg Br. 2009;91(12):1612-7.

13. Harvey D. Assessment of the flexibility of elite athletes using the modified Thomas test. Brit J Sport Med. 1998;32(1):68-70.
14. Lee KM, Chung CY, Kwon DG, Han HS, Choi IH, Park MS. Reliability of physical examination in the measurement of hip flexion contracture and correlation with gait parameters in cerebral palsy. J Bone Joint Surg Am. 2011:93(2):150-8.

15. Bell JS, Thompson WA. Modified spot scanography. Am J Roentgenol Radium Ther. 1950;63(6):915-6.

16. Paley D. Problems, obstacles, and complications of limb lengthening by the Ilizarov technique. Clin Orthop Relat Res. 1990;250:81-104.

17. Weinstein SL, Flynn JM. Lovell and Winter's Pediatric Orthopaedics. 7th ed. Philadelphia: Lippincott Williams \& Wilkins; 2014.

18. Karger C, Guille JT, Bowen JR. Lengthening of congenital lower limb deficiencies. Clin Orthop Relat Res. 1993;291:236-45.

19. Siffert RS. Lower limb-length discrepancy. J Bone Joint Surg Am. 1987; 69(7):1100-6.

20. Lee DY, Choi IH, Chung CY, Chung PH, Chi JG, Suh YL. Effect of tibial lengthening on the gastrocnemius muscle. A histopathologic and morphometric study in rabbits. Acta Orthop Scand. 1993;64(6):688-92.

21. Thorey F, Bruenger J, Windhagen H, Witte F. Muscle response to leg lengthening during distraction osteogenesis. J Orthop Res. 2009;27(4):483-8.

22. De Deyne PG. Lengthening of muscle during distraction osteogenesis. Clin Orthop Relat Res. 2002:403:S171-7.

23. Nayagam $\mathrm{S}$. Femoral lengthening with a rail external fixator: tips and tricks. Strategies Trauma Limb Reconstr. 2010;5(3):137-44.

24. Bhave A, Shabtai L, Woelber E, Apelyan A, Paley D, Herzenberg JE. Muscle strength and knee range of motion after femoral lengthening 2-to 5-year follow-up. Acta Orthop. 2017:88(2):179-84.

25. Husson JL, Mallet JF, Parent H, Cavagna R, Vital JM, Blamoutier A, et al. The lumbar-pelvic-femoral complex: applications in spinal imbalance. Orthop Traumatol Surg Res. 2010;96(4):S1-9.

\section{Ready to submit your research? Choose BMC and benefit from:}

- fast, convenient online submission

- thorough peer review by experienced researchers in your field

- rapid publication on acceptance

- support for research data, including large and complex data types

- gold Open Access which fosters wider collaboration and increased citations

- maximum visibility for your research: over $100 \mathrm{M}$ website views per year

At BMC, research is always in progress.

Learn more biomedcentral.com/submissions 